\title{
ChemComm
}

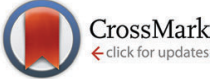

Cite this: Chem. Commun., 2015, 51,5883

Received 24th December 2014, Accepted 23rd February 2015

DOI: $10.1039 / c 4 c c 10298 c$

www.rsc.org/chemcomm

\section{Highly durable carbon-supported Pt catalysts prepared by hydrosilane-assisted nanoparticle deposition and surface functionalization $\dagger$}

\author{
Akinori Saito, ${ }^{a}$ Hiromi Tsuji, ${ }^{b}$ Iwao Shimoyama, ${ }^{c}$ Ken-ichi Shimizu ${ }^{d}$ and \\ Yuta Nishina*be
}

\begin{abstract}
Hydrosilane enabled the formation of $\mathrm{Pt}$ nanoparticles and the silane functionalization of a carbon support material in one pot. The metal/Si-modified carbon composites are highly durable during catalytic methane oxidation.
\end{abstract}

Carbon-supported noble metal composites are used as catalysts in organic synthesis, ${ }^{1}$ fuel cells, ${ }^{2}$ super capacitors, ${ }^{3}$ solar cells, ${ }^{4}$ and sensors. ${ }^{5}$ Support materials composed of $\mathrm{sp}^{2}$ hybridized carbon atoms have advantages of high electron and thermal conductivities, which enhance the performance of the metal species. ${ }^{6}$ In contrast, carbon reacts readily with oxygen to eliminate gaseous carbon oxides upon heating especially in the presence of metal species, and thus catalytic combustion occurs rapidly. Therefore, the development of thermally durable carbon materials is of great importance. ${ }^{7}$ The preparation of metal-supported carbon materials covered with silica layers has been reported and they have been used as catalysts for cyclohexane dehydrogenation. ${ }^{8}$ However, multistep functionalization processes such as (1) the deposition of metal nanoparticles onto carbon, (2) surface treatment with a silane coupling agent, and (3) silica-layer formation by the hydrolysis of an alkoxysilane are required.

We focused on the development of a one-pot synthesis of a metal/Si-modified carbon composite with high thermal durability. To achieve this we used hydrosilane $\left(\mathrm{R}_{3} \mathrm{SiH}\right)$ as the dual-role reagent for the metal nanoparticle formation and for the surface modification of the carbon support. Hydrosilanes can reduce metal salts

\footnotetext{
${ }^{a}$ Graduate School of Natural Science and Technology, Okayama University, 3-1-1, Tsushimanaka, Kita-ku, Okayama 700-8530, Japan

${ }^{b}$ Research Core for Interdisciplinary Sciences, Okayama University, 3-1-1, Tsushimanaka, Kita-ku, Okayama 700-8530, Japan.

E-mail: nisina-y@cc.okayama-u.ac.jp

'Japan Atomic Energy Agency, Quantum Beam Science Directorate, Tokai-mura, Naka-gun, Ibaraki 319-1195, Japan

${ }^{d}$ Catalysis Research Centre, Hokkaido University, Kita21, Nishi10, Kita-ku, Sapporo, Hokkaido 001-0021, Japan

${ }^{e}$ Precursory Research for Embryonic Science and Technology, Japan Science and Technology Agency, 4-1-8 Honcho, Kawaguchi, Saitama 332-0012, Japan $\dagger$ Electronic supplementary information (ESI) available. See DOI: 10.1039/ c4cc10298c
}

$\left(\mathrm{M}^{n+2}\right)$ to metal nanoparticles $\left(\mathrm{M}^{n}\right)$ through transmetallation or by ligand exchange. A successive reductive elimination ${ }^{9}$ is accompanied by the formation of $\mathrm{R}_{3} \mathrm{SiX}(\mathrm{X}=$ the counter anion of $\mathrm{M}^{n+2}$ or $\mathrm{OH}$ ) that functions as a silane coupling agent ${ }^{10}$ towards $\mathrm{OH}$ groups on the carbon support. Among the various carbon-based support materials, we initially focused on graphene oxide (GO) because of its highly oxygenated and two-dimensional nanosheet structure. This allows for uniform nanoparticle distribution and silane functionalization. The thermal resistance of the composites was evaluated by a catalytic methane oxidation reaction. This reaction requires high energy because of the high $\mathrm{C}-\mathrm{H}$ bond dissociation energy $\left(104 \mathrm{kcal} \mathrm{mol}^{-1}\right){ }^{11}$

A Pt/GO composite ( $\mathrm{Pt} / \mathrm{SiGO}$ ) was prepared from $\mathrm{GO}$ and $\mathrm{PtCl}_{2}$ using $\mathrm{Et}_{3} \mathrm{SiH}$ as a reductant. ${ }^{12}$ The mixture was stirred at room temperature for $1 \mathrm{~h}$ and then heated to $95{ }^{\circ} \mathrm{C}$ for $6 \mathrm{~h}$ (Scheme 1-1). For comparison, $\mathrm{PtCl}_{2}$ was reduced by ethylene glycol (Pt/GO-EG, Scheme 1-2) or $\mathrm{NaBH}_{4}$ (Pt/GO-NaBH Scheme 1-3).

The amount of Pt on Pt/SiGO was found to be $4.2 \mathrm{wt} \%$ by energy dispersive X-ray (EDX) spectroscopy (Table 1, entry 1). $1.5 \mathrm{wt} \%$ Si was also detected by EDX. The Pt nanoparticles on the surface of GO were characterized by X-ray diffraction (XRD). The XRD patterns of graphite, GO, and Pt/SiGO are shown in Fig. 1 . The peak at $2 \theta=10.3^{\circ}$ in the XRD pattern corresponds to GO (002), and the broad peak at around $2 \theta=23^{\circ}$ is attributed to the stacked graphene sheets produced by the reduction of GO. ${ }^{13}$ For Pt/SiGO the peaks are at $2 \theta=39.7,46.2$, and $67.6^{\circ}$ and these peaks correspond to the (111), (200), and (220) planes

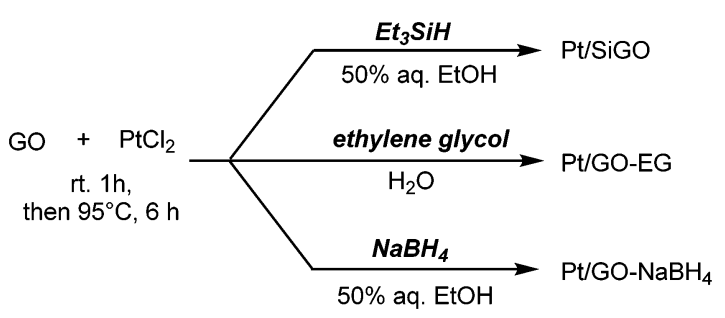

Scheme 1 Preparation of the Pt composites. 
Table 1 Pt content of the catalysts as determined by EDX

\begin{tabular}{lllll}
\hline Entry & Catalyst & Reductant & Support & Pt content (wt\%) \\
\hline 1 & $\mathrm{Pt} / \mathrm{C}$ & $-^{a}$ & $\mathrm{C}$ & 5.0 \\
2 & $\mathrm{Pt} / \mathrm{SiGO}$ & $\mathrm{Et}_{3} \mathrm{SiH}$ & $\mathrm{GO}$ & 4.2 \\
3 & $\mathrm{Pt} / \mathrm{GO}-\mathrm{NaBH}_{4}$ & $\mathrm{NaBH}_{4}$ & $\mathrm{GO}$ & 5.9 \\
4 & $\mathrm{Pt} / \mathrm{GO}-\mathrm{EG}$ & $\mathrm{EG}$ & $\mathrm{GO}$ & 3.5 \\
\multicolumn{2}{l}{ Unknown (commercial product). } & &
\end{tabular}

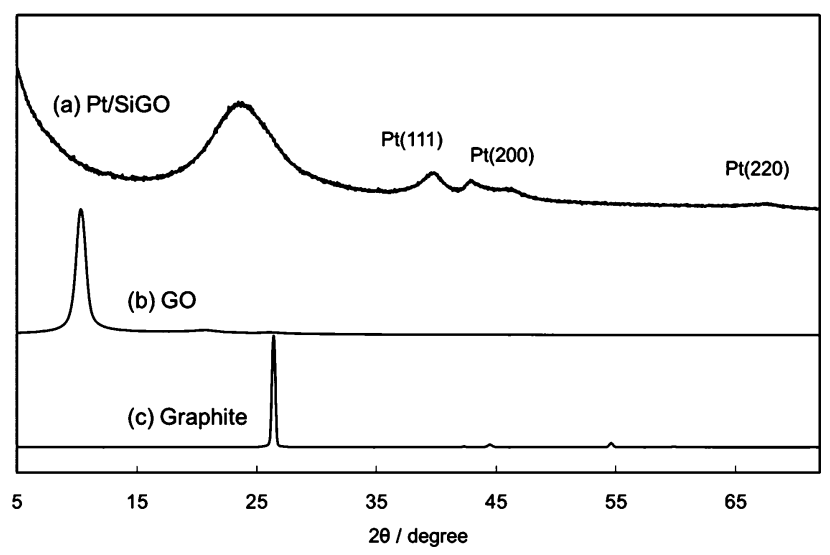

Fig. 1 XRD spectra of (a) Pt/SiGO, (b) GO, and (c) graphite.
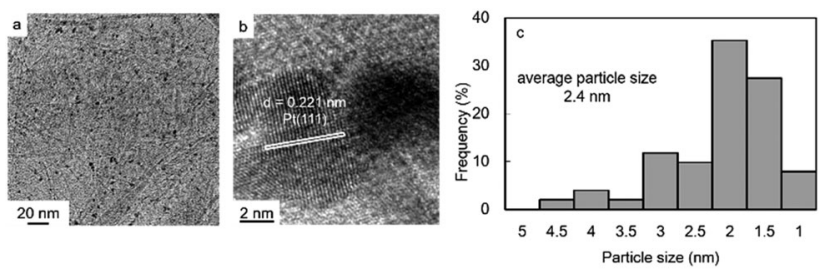

Fig. 2 (a, b) TEM images of Pt/SiGO, and (c) the particle size distribution.

of a face-centered cubic (fcc) Pt crystal, respectively. ${ }^{14}$ The morphology of the Pt nanoparticles was observed using a transmission electron microscope (TEM) (Fig. 2). The average particle size of the Pt nanoparticles was $2.4 \mathrm{~nm}$. The lattice space of the Pt nanoparticles was $0.22 \mathrm{~nm}$, which corresponds to the (111) plane of a Pt crystal. ${ }^{14}$

The thermal durability of $\mathrm{Pt} / \mathrm{SiGO}$ was evaluated by the catalytic methane oxidation reaction (Fig. 3), because this reaction requires high temperature. For comparison, commercially available $\mathrm{Pt} / \mathrm{C}$ and $\mathrm{Pt} / \mathrm{GO}$ composites prepared using ethylene glycol (Pt/GO-EG) or $\mathrm{NaBH}_{4}\left(\mathrm{Pt} / \mathrm{GO}-\mathrm{NaBH}_{4}\right)^{15}$ were also evaluated. ${ }^{16}$ Catalysts containing $10 \mathrm{mg}$ of Pt, as determined by EDX (Table 1), were subjected to treatment with a gas containing $7 \%$ methane, $33 \% \mathrm{O}_{2}$, and $60 \% \mathrm{He}$ at $400{ }^{\circ} \mathrm{C}$. The flow rate was $30 \mathrm{~mL} \mathrm{~min}{ }^{-1}$ and the conversion of methane was measured by gas chromatography (Fig. S2, ESI $\dagger$ ). For Pt/C (Fig. 3a) the catalytic activity decreased significantly after $40 \mathrm{~min}$ while $\mathrm{Pt} / \mathrm{SiGO}$ maintained its activity (Fig. $3 \mathrm{~b}$ ). The $\mathrm{Pt} / \mathrm{GO}$ prepared using ethylene glycol (Pt/GO-EG) (Fig. 3c) or $\mathrm{NaBH}_{4}\left(\mathrm{Pt} / \mathrm{GO}-\mathrm{NaBH}_{4}\right)$ (Fig. 3d) did not show high activity at any point.

The recovered catalysts were analyzed by TEM (Fig. 4). The original Pt/C contained $3.3 \mathrm{~nm}$ Pt nanoparticles (Fig. 4a); however, after methane oxidation almost all the carbon support

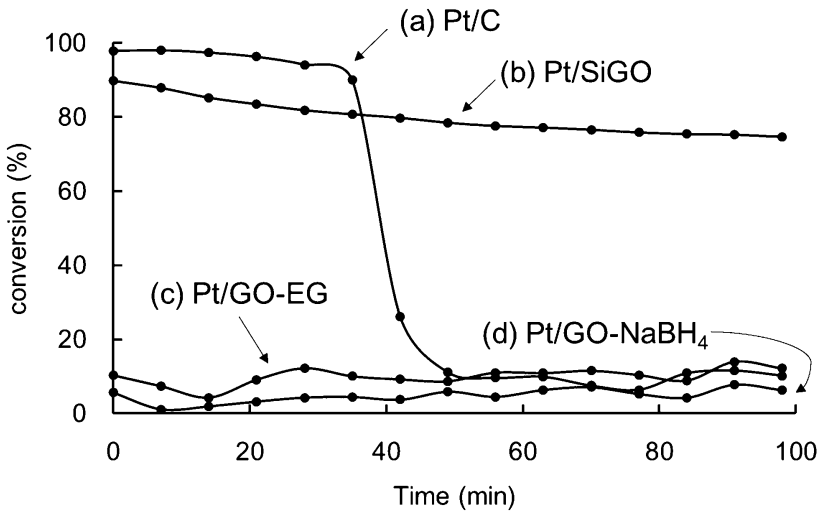

Fig. 3 Time course of the catalytic activity of methane conversion under oxygen at $400{ }^{\circ} \mathrm{C}$. (a) $\mathrm{Pt} / \mathrm{C}$, (b) Pt/SiGO, (c) Pt/GO-EG, and (d) $\mathrm{Pt} / \mathrm{GO}-\mathrm{NaBH}_{4}$.
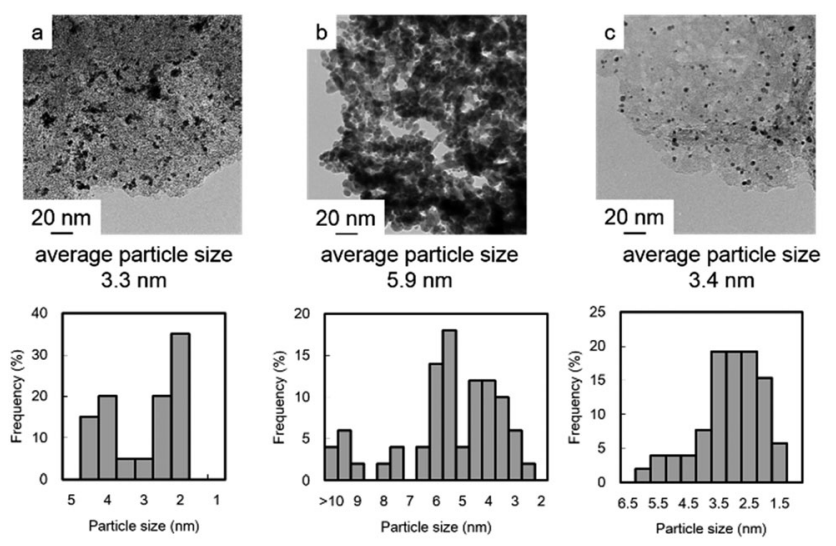

Fig. 4 TEM images and particle size distributions of (a) fresh $\mathrm{Pt} / \mathrm{C}$, (b) recovered $\mathrm{Pt} / \mathrm{C}$, and (c) recovered $\mathrm{Pt} / \mathrm{SiGO}$.

disappeared and nanoparticle grain growth occurred (Fig. 4b). In contrast, the recovered $\mathrm{Pt} / \mathrm{GO}$ that was prepared using $\mathrm{Et}_{3} \mathrm{SiH}$ did not undergo such a drastic structural change. Its particle size increased slightly from $2.4 \mathrm{~nm}$ (Fig. 2) to $3.4 \mathrm{~nm}$ (Fig. 4c).

XPS was measured before and after the methane oxidation reaction. The intensities of each spectra were normalized to that of the Pt $4 f_{7 / 2}$ and $4 f_{5 / 2}$ regions (65-76 eV), because we hypothesized that the amount of Pt does not change before and after the reaction. For Pt/SiGO, the intensity of the Si $2 \mathrm{p}$ and $2 \mathrm{~s}$ regions (99 and $151 \mathrm{eV}$ ) increased after the reaction at $400{ }^{\circ} \mathrm{C}$ (Fig. 5A). This suggests that silyl functional groups were covalently attached to $\mathrm{GO}$ because the boiling points of $\mathrm{Et}_{3} \mathrm{SiH}$ and $\mathrm{Et}_{3} \mathrm{SiOH}$ are only 107 and $158^{\circ} \mathrm{C}$, respectively. The increase in $\mathrm{Si}$ indicates that other elements such as $\mathrm{C}$ and $\mathrm{O}$ were removed and, therefore, XPS spectra of the $\mathrm{C} 1 \mathrm{~s}$ regions were analyzed. As expected, the intensities of the $\mathrm{C} 1 \mathrm{~s}$ regions of $\mathrm{Pt} / \mathrm{SiGO}$ after the methane oxidation reaction decreased; however, the decrease is much smaller than that of Pt/C (Fig. 5B).

$\mathrm{Si}$ atoms were well dispersed over GO as determined by scanning transmission electron microscopy (STEM)-EDX mapping (Fig. S3, ESI†). The hydroxyl groups on GO are known to react with silane coupling reagents (silyl chlorides) to form silylated GO. ${ }^{17}$ Here, we used $\mathrm{Et}_{3} \mathrm{SiH}$ to reduce $\mathrm{Pt}(\mathrm{II})$ to Pt nanoparticles and, as a 
A

B
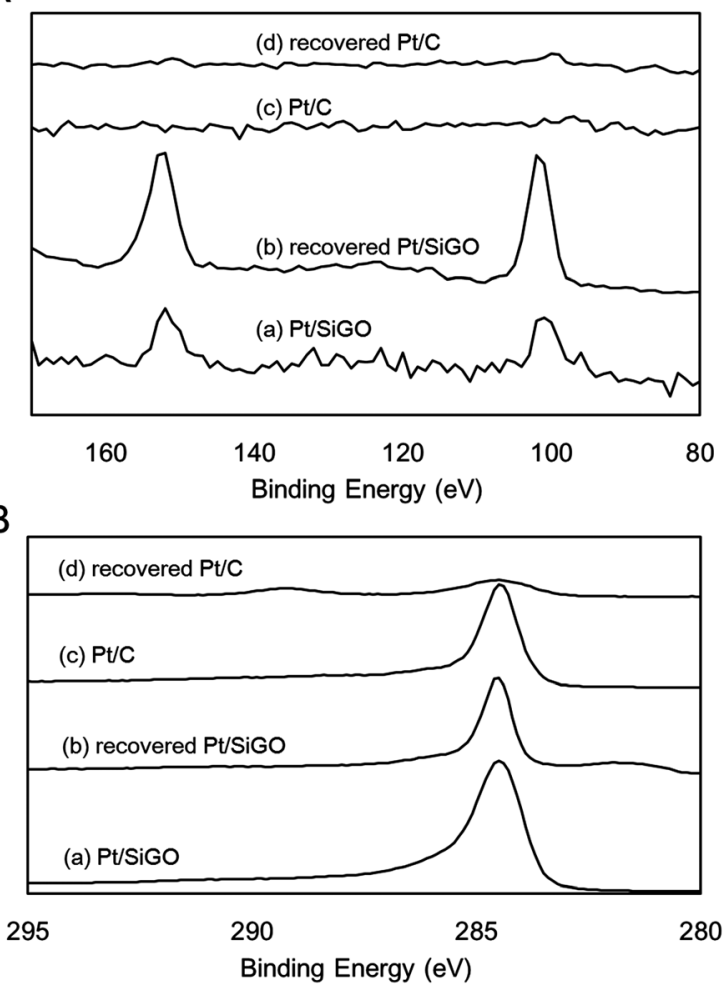

Fig. 5 XPS of (A) Si 2p and 2s, and (B) the $\mathrm{C} 1$ s regions of Pt/SiGO and Pt/C before and after the methane oxidation reaction.

result, $\mathrm{Et}_{3} \mathrm{SiOH}$ is produced..$^{18} \mathrm{Et}_{3} \mathrm{SiOH}$ can also function as a silane coupling reagent ${ }^{10}$ and, therefore, the $\mathrm{OH}$ groups on GO are functionalized with $\mathrm{Et}_{3} \mathrm{Si}$ groups via dehydrative condensation. To determine the chemical state of Si on GO, an X-ray absorption near edge structure (XANES) spectrum of Pt/SiGO was obtained. Si(0) and $\mathrm{SiO}_{2}$ have peaks at 1842 and $1848 \mathrm{eV}$, respectively (Fig. 6a and b). ${ }^{19}$ The XANES spectrum of the $\mathrm{Et}_{3} \mathrm{Si}$-modified $\mathrm{GO}\left(\mathrm{Et}_{3} \mathrm{Si}-\mathrm{GO}\right)$, produced using $\mathrm{Et}_{3} \mathrm{SiCl}$, had peaks at $1845 \mathrm{eV}$ and $1848 \mathrm{eV}$ (Fig. 6c). For $\mathrm{Pt} / \mathrm{SiGO}$ a similar spectrum to that of $\mathrm{Et}_{3} \mathrm{Si}-\mathrm{GO}$ was obtained (Fig. 6d). This suggests that the $\mathrm{Et}_{3} \mathrm{Si}$ groups are attached to $\mathrm{Pt} / \mathrm{SiGO}$ by silyl ether bonds. ${ }^{20}$ Fourier transform infrared

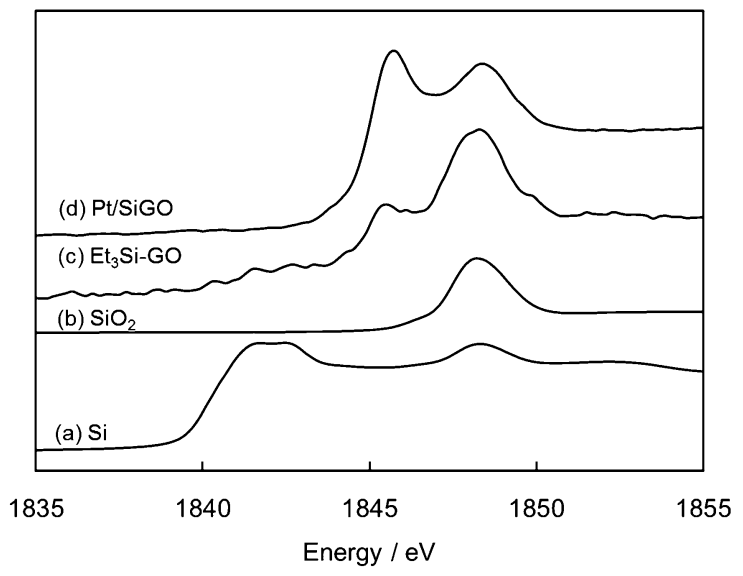

Fig. 6 Si K-edge XANES spectra of (a) $\mathrm{Si}(0)$, (b) $\mathrm{SiO}_{2}$, (c) $\mathrm{Et}_{3} \mathrm{Si}$-modified $\mathrm{GO}$, and (d) Pt/SiGO.

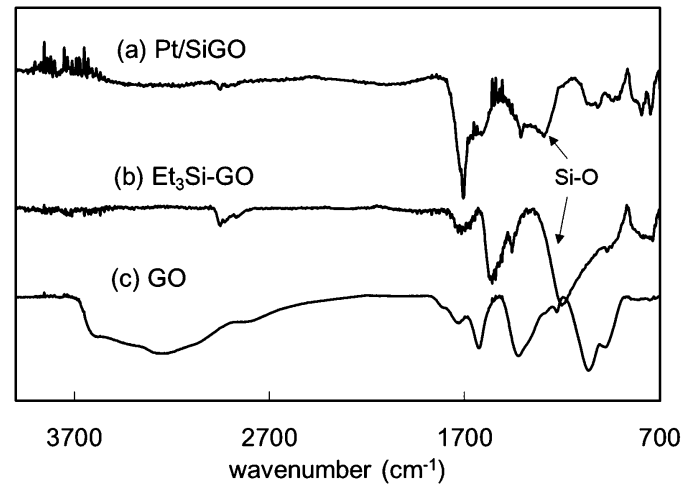

Fig. 7 FT-IR spectra of (a) Pt/SiGO, (b) Et $3 \mathrm{Si}-\mathrm{GO}$, and (c) GO.

(FT-IR) spectroscopy of Pt/SiGO also supports the presence of the $\mathrm{Et}_{3} \mathrm{Si}$ groups; peaks of alkyl chains were observed at 2740$2980 \mathrm{~cm}^{-1}$ (Fig. 7). Si-O bond has a strong IR absorption at 1100-1200 $\mathrm{cm}^{-1}$, which is observed for both Pt/SiGO (Fig. 7a) and $\mathrm{Et}_{3} \mathrm{Si}-\mathrm{GO}$ (Fig. $7 \mathrm{~b}$ ).

To clarify the durability of $\mathrm{Pt} / \mathrm{SiGO}$ under heating, thermogravimetric analysis (TGA) was conducted (DTA is shown in Fig. S4, $\mathrm{ESI}+$ ). A drastic weight loss was observed at $350{ }^{\circ} \mathrm{C}$ on $\mathrm{Pt} / \mathrm{C}$ under air. $\mathrm{Pt} / \mathrm{SiGO}$ and $\mathrm{Pt} / \mathrm{GO}-\mathrm{NaBH}_{4}$ showed higher thermal durability; however, the obvious effect of silyl functionalization was not observed (Fig. 8). These results suggest that the silyl group does not affect carbon supports, but stabilizes Pt particles. The weight loss of $\mathrm{Pt} / \mathrm{SiGO}$ at $50-100{ }^{\circ} \mathrm{C}$ would derive from the desorption of water, and the loss at $100-350{ }^{\circ} \mathrm{C}$ would derive from the removal of residual oxygen functional groups and alkyl chains, which were also supported by IR analysis (Fig. S5, ESI†).

The hydrosilane-assisted deposition of Pt also enhanced the thermal durability of activated carbon (Pt/SiC) (Fig. 9a). Interestingly, treatment of the commercially available $\mathrm{Pt} / \mathrm{C}$ with $\mathrm{Et}_{3} \mathrm{SiH}$ ( $\mathrm{Pt} / \mathrm{C}-\mathrm{Et}_{3} \mathrm{SiH}$ ) also showed improved durability (Fig. 9b) compared with the as-obtained compound (Fig. 9c).

We developed a one-pot synthesis of Pt/Si-modified carbon composites. Si atoms were uniformly present on the carbon

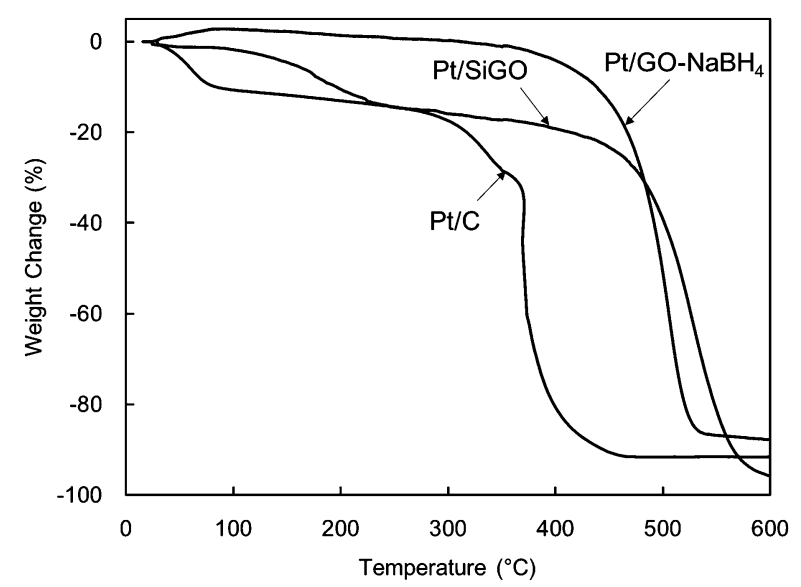

Fig. $8 \mathrm{TGA}$ of $\mathrm{Pt} / \mathrm{SiGO}, \mathrm{Pt} / \mathrm{C}$, and $\mathrm{Pt} / \mathrm{GO}-\mathrm{NaBH}_{4}$ under air. Heating rate: $2{ }^{\circ} \mathrm{Cmin}^{-1}$ 


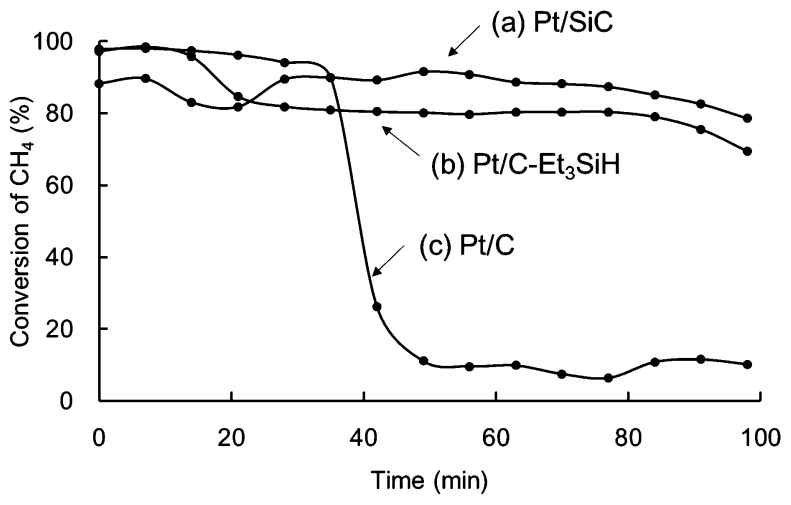

Fig. 9 Catalytic activities of the hydrosilane-treated catalysts.

surface upon dehydrative silyl ether formation between $\mathrm{Et}_{3} \mathrm{SiOH}$ and the $\mathrm{OH}$ group of the carbon. The thermal durability of the composite during methane oxidation improved upon silyl group modification. This work was partly supported by the Nanotechnology Platform Program, JST PRESTO, KAKENHI of the Ministry of Education, Culture, Sports, Science and Technology, and the Cooperative Research Program of Catalysis Research Centre, Hokkaido University. We acknowledge Dr Hideki Hashimoto for STEM-EDS measurements.

\section{Notes and references}

1 (a) H. Sakurai, T. Tsukuda and T. Hirao, J. Org. Chem., 2002, 67, 2721; (b) T. Maegawa, Y. Kitamura, S. Sako, T. Udzu, A. Sakurai, A. Tanaka, Y. Kobayashi, K. Endo, U. Bora, T. Kurita, A. Kozaki, Y. Monguchi and H. Sajik, Chem. - Eur. J., 2007, 13, 5937; (c) L. Yin and J. Liebscher, Chem. Rev., 2007, 107, 133; (d) F. X. Felpin, T. Ayad and S. Mitra, Eur. J. Org. Chem., 2006, 2679. 2 (a) P. J. Ferreira, G. J. La Ó, Y. Shao-Horn, D. Morgan, R. Makharia, S. Kocha and H. A. Gasteiger, J. Electrochem. Soc., 2005, 152, A2256; (b) Y. Shao, G. Yin, Y. Gao and P. Shi, J. Electrochem. Soc., 2006, 153, A1093; (c) Z. Zhou, S. Wang, W. Zhou, G. Wang, L. Jiang, W. Li, S. Song, J. Liu, G. Sun and Q. Xin, Chem. Commun., 2003, 394; (d) J. R. Varcoe, R. C. T. Slade, G. L. Wright and Y. Chen, J. Phys. Chem. B, 2006, 110, 21041.

3 G. Y. Yu, W. X. Chen, Y. F. Zheng, J. Zhao, X. Li and Z. D. Xu, Mater. Lett., 2006, 60, 2453.

4 Y. H. Ng, I. Lightcap, K. Goodwin, M. Matsumura and P. V. Kamat, J. Phys. Chem. Lett., 2010, 1, 2222.
5 I. V. Lightcap, S. Murphy, T. Schumer and P. V. Kamat, J. Phys. Chem. Lett., 2012, 3, 1453.

6 (a) A. Kongkanand, K. Vinodgopal, S. Kuwabata and P. V. Kamat, J. Phys. Chem. B, 2006, 110, 16185; $(b)$ R. Muszynski, B. Seger and P. V. Kamat, J. Phys. Chem. C, 2008, 112, 5263; (c) K.-S. Ha, G. Kwak, K.-W. Jun, J. Hwang and J. Lee, Chem. Commun., 2013, 49, 5141.

7 L. D. Rogatis, M. Cargnello, V. Gombac, B. Lorenzut, T. Montini and P. Fornasiero, ChemSusChem, 2010, 3, 24.

8 (a) K. Nakagawa, T. Okayama, Y. Tanimoto, K. Sotowa, S. Sugiyama, T. Moriga, S. Takenaka and M. Kishida, Appl. Catal., A, 2012, 419, 13; (b) K. Nakagawa, T. Hoshinoo, K. Sotowa, S. Sugiyama, L. Rkiouak, V. Dubois and S. Hermans, Chem. Lett., 2012, 41, 1308; (c) K. Nakagawa, Y. Tanimoto, T. Okayama, K. Sotowa, S. Sugiyama, S. Takenaka and M. Kishida, Catal. Lett., 2010, 136, 71; (d) S. Takenaka, T. Iguchi, E. Tanabe, H. Matsune and M. Kishida, Carbon, 2009, 47, 1251; (e) S. Takenaka, H. Matsumori, K. Nakagawa, H. Matsune, E. Tanabe and M. Kishida, J. Phys. Chem. Lett., 2007, 111, 15133; (f) S. Takenaka, T. Arike, H. Matsune, E. Tanabe and M. Kishida, J. Catal., 2008, 257, 345. 9 (a) L. N. Lewis and N. Lewis, J. Am. Chem. Soc., 1986, 108, 7228; (b) B. Fu, M. N. Missaghi, C. M. Downing, M. C. Kung, H. H. Kung and G. Xiao, Chem. Mater., 2010, 22, 2181.

10 Y. Xie, C. A. S. Hill, Z. Xiao, H. Militz and C. Mai, Composites, Part A, 2010, 41, 806.

11 S. J. Blanksby and G. B. Ellison, Acc. Chem. Res., 2003, 36, 255.

$12 \mathrm{Pt}$ nanoparticle formation with other hydrosilanes was also investigated. See ESI $\dagger$.

13 P. Cui, J. Lee, E. Hwang and H. Lee, Chem. Commun., 2011, 47, 12370.

14 Powder Diffraction File No. 04-0802.

15 (a) B. Seger and P. V. Kamat, J. Phys. Chem. Lett., 2009, 113, 7990; (b) Y. Li, L. Tang and J. Li, Electrochem. Commun., 2009, 11, 846; (c) J. D. Qiu, G. C. Wang, R. P. Liang, X. H. Xia and H. W. Yu, J. Phys. Chem. C, 2011, 115, 15639; (d) Y. Li, W. Gao, L. Ci, C. Wang and P. M. Ajayan, Carbon, 2010, 48, 1124.

16 The surface area of graphene oxide derivatives determined by the BET method is generally small $\left(<100 \mathrm{~m}^{2} \mathrm{~g}^{-1}\right)$. We measured the surface area by methylene blue adsorption. Pt/SiGO: $534 \mathrm{~m}^{2} \mathrm{~g}^{-1}$, Pt/GO-NaBH 4 : $744 \mathrm{~m}^{2} \mathrm{~g}^{-1}$, Pt/GO-EG: $921 \mathrm{~m}^{2} \mathrm{~g}^{-1}$, Pt/C: $1162 \mathrm{~m}^{2} \mathrm{~g}^{-1}$, and GO: $1292 \mathrm{~m}^{2} \mathrm{~g}^{-1}$. See ESI $\dagger$ for more details.

17 (a) Y. Matsuo, T. Tabata, T. Fukunaga, T. Fukutsuka and Y. Sugie, Carbon, 2005, 43, 2875; (b) Y. Matsuo, T. Fukunaga, T. Fukutsuka and Y. Sugie, Carbon, 2004, 42, 2113.

18 (a) K. Shimizu, T. Kubo and A. Satsuma, Chem. - Eur. J., 2012, 18, 2226; (b) B. P. S. Chauhan, A. Sarkar, M. Chauhan and A. Roka, Appl. Organomet. Chem., 2009, 23, 385; (c) M. Jeon, J. Han and J. Park, ACS Catal., 2012, 2, 1539.

19 Y. Baba, T. Sekiguchi, I. Shimoyama and N. Hirao, Surf. Sci., 2013, 612, 77.

$20 \mathrm{Si}$ K-edge XANES was also studied by the DV-X $\alpha$ molecular-orbital calculation method. The presence of two peaks in XANES spectra suggested the existence of $\mathrm{Si}-\mathrm{O}$ and $\mathrm{Si}-\mathrm{C}$ bonds. See ESI $\dagger$. 